\title{
Case Report Effect of Prolonged Discontinuation of L-Thyroxine Replacement in a Child with Congenital Hypothyroidism
}

\author{
Rita Ann Kubicky, ${ }^{1,2}$ Evan Weiner, ${ }^{2,3}$ Bronwyn Carlson, ${ }^{2}$ and Francesco De Luca ${ }^{1,2}$ \\ ${ }^{1}$ Section of Endocrinology and Diabetes, St. Christopher's Hospital for Children, Drexel University College of Medicine, \\ Philadelphia, PA 19134, USA \\ ${ }^{2}$ Department of Pediatrics, Drexel University College of Medicine, Philadelphia, PA 19102, USA \\ ${ }^{3}$ Department of Emergency Medicine, St. Christopher's Hospital for Children, Drexel University College of Medicine, \\ Philadelphia, PA 19134, USA
}

Correspondence should be addressed to Rita Ann Kubicky, ritaann.kubicky@tenethealth.com

Received 13 January 2012; Accepted 16 February 2012

Academic Editors: T. Kita and R. Murray

Copyright (C) 2012 Rita Ann Kubicky et al. This is an open access article distributed under the Creative Commons Attribution License, which permits unrestricted use, distribution, and reproduction in any medium, provided the original work is properly cited.

\begin{abstract}
When diagnosed through neonatal screening and treated promptly and adequately, infants with congenital hypothyroidism $(\mathrm{CH})$ experience normal physical growth and neurological development. Here we present a 3-year-old boy diagnosed with $\mathrm{CH}$ as a newborn, who was subsequently left untreated and experienced significant growth failure and developmental delay. This case emphasizes the importance of a consistent adherence to treatment in preventing such complications, especially in infancy and early childhood.
\end{abstract}

\section{Introduction}

The prevalence of congenital hypothyroidism $(\mathrm{CH})$ in the past has been approximately 1 in 3,000 to 1 in 4,000 births with a higher incidence in Hispanic individuals [1]. More recent data suggest an increased prevalence of $\mathrm{CH}$ in the United States, possibly reflecting changes in screening methods $[2,3] . \mathrm{CH}$ is the most frequent endocrine disease in infants, and, in most cases, the disorder is permanent [1]. When diagnosed and treated promptly and adequately, children born with $\mathrm{CH}$ experience normal physical growth and neurological development. Here we present a 3-year-old boy diagnosed at birth with congenital hypothyroidism, with subsequent poor compliance with L-thyroxine replacement.

\section{Case Presentation}

J. D. is a $211 / 12$-year-old male, born in Mexico and diagnosed by neonatal screening with $\mathrm{CH}$. He was then treated with L-thyroxine for approximately 1 year, until his mother lost her health insurance coverage and could not purchase the medication. Shortly after his family immigrated to the
United States, J. D. was taken to St. Christopher's Hospital for Children's (SCHC) Emergency Department (ED) for evaluation.

His mother described a history of developmental delay, especially affecting his motor and language skills, as well as a history of constipation. Upon physical examination (PE), J. D.'s vital signs were as follows: temperature $(T)$ of $97.6^{\circ} \mathrm{F}$, heart rate (HR) of 95 beats per minute, blood pressure (BP) of $95 / 54 \mathrm{mmHg}$, and respiratory rate (RR) of 20 breaths per minute. His weight and length were both below the 3rd percentile (statural age of an $81 / 2$-month old). J. D. was able to sit and crawl but could not stand or walk; he could only bear weight on his legs with support. The rest of his PE was significant for coarse facial features (Figures 1 and 2), macroglossia (Figure 1), a protuberant abdomen and a small umbilical hernia (Figure 3), and dry skin. His thyroid was not palpable. The serum TSH was very elevated $(1,620 \mathrm{mIU} / \mathrm{L})$ and the free T4 and thyroglobulin undetectable (Table 1); his serum prolactin level was mildly elevated $(27.9 \mathrm{ng} / \mathrm{mL})$. On the day of presentation, J. D. was placed on $50 \mu \mathrm{g} \mathrm{L-}$ thyroxine daily $(\sim 5 \mu \mathrm{g} / \mathrm{kg} / \mathrm{day})$, and a follow-up evaluation was arranged. 


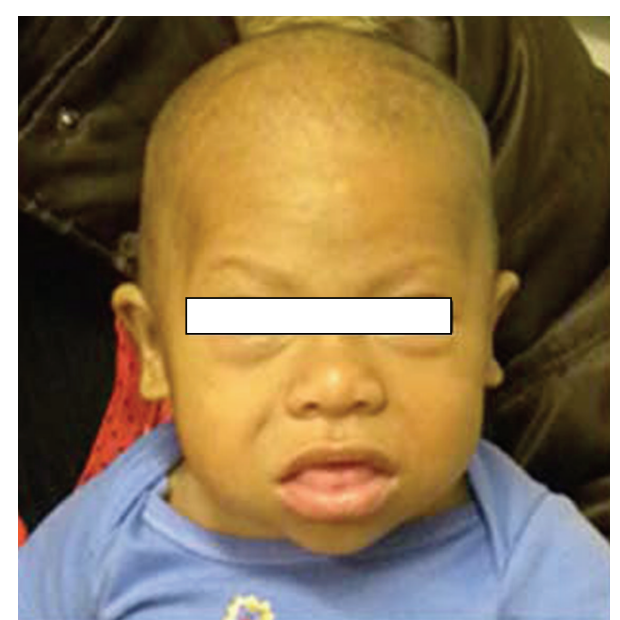

Figure 1: Photograph of patient demonstrating his coarse facial features and macroglossia.

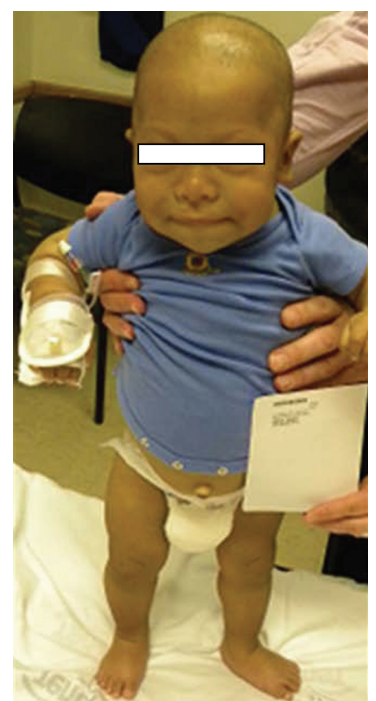

Figure 2: Patient stands with support. His height was significantly below the 3 rd percentile (statural height of a 8 1/2-month-old male).

When evaluated at the SCHC Endocrinology Outpatient Clinic 2 weeks later, his mother reported increased activity, alertness, and appetite. In addition, his constipation had improved and he was less sleepy. His PE was virtually unchanged when compared to the one obtained in the ED. His dentition was delayed, with only 12 erupted teeth. His testicular volume was $4 \mathrm{cc}$ bilaterally and he had no pubic hair.

A thyroid ultrasound revealed thyroid hypoplasia, with the right lobe measuring $5 \mathrm{~mm}$ anteriorly posteriorly (AP) and $6 \mathrm{~mm}$ in width $(W)$, and the left lobe measuring $4 \mathrm{~mm}$ $(\mathrm{AP}) \times 9 \mathrm{~mm}(W)$. Upon evaluation by a pediatric neurologist, his psychomotor developmental stage was found to be at the 18-month-old level for personal/social, fine motor/adaptive and language skills; his gross motor skills were at the 12-month-old level (by Denver's scale). His muscle tone

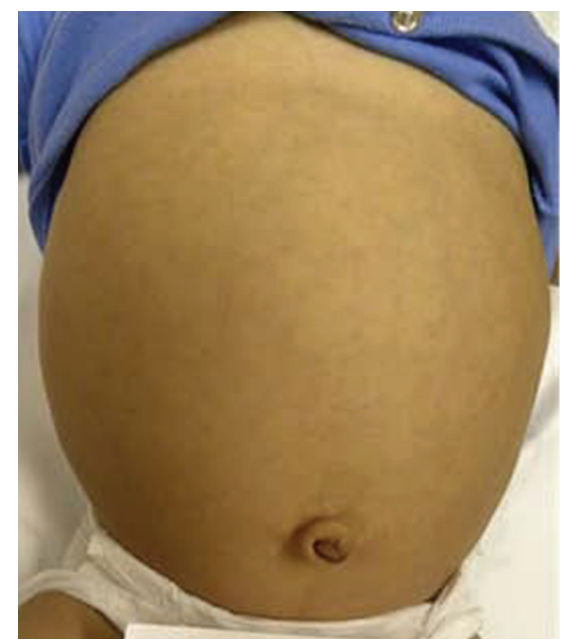

Figure 3: Protuberant abdomen and a small umbilical hernia.

was mildly but symmetrically decreased in all extremities, and his deep tendon reflexes were decreased.

J. D. was evaluated again at the Endocrinology Clinic 4 months after his initial visit to the ED. His mother reported that he had increased strength, which he was pulling to stand, trying to walk, and was much more active and alert. His testicular size was prepubertal. Laboratory studies revealed normal serum TSH and a free T4 (2.84 mIU/L and $1.5 \mathrm{ng} / \mathrm{dL}$, resp.). Serum prolactin was also normal (Table 1$)$.

After being treated with L-thyroxine for 7 months, J. D. grew $8 \mathrm{~cm}$. He was enrolled in an early interventional program to improve his developmental skills. As per his mother, his vocabulary included more words and he was able to go up steps; he had also started to feed himself without help. Although his free T4 was normal $(1.1 \mathrm{ng} / \mathrm{dL})$, his TSH was found to be elevated (20.93 mIU/L).

J. D. was subsequently lost to followup for a few months because of change of insurance. Multiple attempts to contact his mother by phone and by certified mail were unsuccessful. He did not return to our clinic until 9 months later (16 months after his initial presentation): J. D. had grown $9.4 \mathrm{~cm}$ since his previous clinic visit ( 9 months prior). His maternal grandmother reported that he was a very active child who enjoyed singing and dancing. She described that his motor and language skills continued to improve: he was able to run, walk up and down stairs and he knew many words in both English and Spanish. His grandmother stated that his pediatrician at a local health center had been checking his thyroid function tests periodically. His grandmother also stated that J. D.'s dose of L-thyroxine had been increased to $75 \mathrm{mcg}$ 2 months prior by his pediatrician; repeat thyroid function tests 1 month after the dose change were reported as normal. At our endocrinology clinic, thyroid function tests were obtained and a bone age study requested; a follow-up visit with his pediatric neurologist was also recommended. J. D.'s thyroid function tests revealed a normal TSH $(0.79 \mathrm{mIU} / \mathrm{L})$ and a borderline-high free $\mathrm{T} 4(1.7 \mathrm{ng} / \mathrm{dL})$; as a result, the L-thyroxine dose was unchanged. His bone age, obtained one month after the last visit, was delayed (between 2 years 
TABLE 1: Initial and follow-up laboratory studies.

\begin{tabular}{|c|c|c|c|c|c|}
\hline & Initial & 6 weeks & 4 months & 7 months & 16 months \\
\hline TSH (mIU/L) & 1620 & 5.2 & 2.84 & 20.93 & 0.79 \\
\hline Free T4 $(\mathrm{ng} / \mathrm{dL})^{1}$ & $<0.10(<1.29)$ & $1.41(18.15)$ & $1.5(19.30)$ & $1.1(14.16)$ & $1.7(21.88)$ \\
\hline Prolactin $(\mathrm{ng} / \mathrm{mL})^{2}$ & $27.9(1,213.04)$ & $10.1(439.13)$ & $5.1(221.74)$ & - & - \\
\hline Thyroglobulin $(\mathrm{ng} / \mathrm{mL})^{3}$ & $<0.5(<0.5)$ & - & - & - & - \\
\hline
\end{tabular}

Values in Systeme International (SI) units are in parentheses.

${ }^{1}$ To convert to $\mathrm{pmol} / \mathrm{L}$ multiply by 12.87 .

${ }^{2}$ To convert to $\mathrm{pmol} / \mathrm{L}$ multiply by 43.478 .

${ }^{3}$ To convert to $\mu \mathrm{g} / \mathrm{L}$ multiply by 1 .

8 months and 3 years at the chronological age of 4 years and 5 months).

\section{Discussion}

Thyroid hormones play an essential role in normal statural growth: in fact, growth failure is a known complication of congenital hypothyroidism $(\mathrm{CH})$. Before the neonatal screening was initiated in the 1970s, the percentage of children with $\mathrm{CH}$ having a height below the 10th percentile has been shown to range from $19 \%$ to $31 \%[4,5]$. After the introduction of the screening, several studies have reported a normal linear growth in infancy and childhood [6-8], while others have described a slight growth deceleration early in childhood in children with severe $\mathrm{CH}$ at diagnosis [9-11]. With respect to the achievement of a normal final height, some studies have suggested that the adequacy of L-thyroxine replacement in the first 6 months of life may influence the adult height of children with $\mathrm{CH}$ detected by newborn screening [12]. In contrast, other studies have found no correlation between severity at diagnosis, etiology, or initial L-thyroxine dosage $[13,14]$. The only postnatal factor consistently found to be related to adult height has been the age at the start of treatment. Interestingly, longstanding untreated $\mathrm{CH}$ has been associated with permanent height loss. Boersma et al. have described two children with $\mathrm{CH}$, who were left untreated for several years; although they experienced a marked catch-up growth, both of them reached an adult height below their target height [15].

It is well known that $\mathrm{CH}$ diagnosed on clinical grounds would often lead to severe cognitive and motor delays. Studies of children diagnosed in the prescreening era have reported that $8 \%$ to $29 \%$ patients affected by $\mathrm{CH}$ developed intellectual disability (i.e., IQ below 70) $[5,16,17]$.

In contrast, a number of longitudinal studies of cohorts of children diagnosed with $\mathrm{CH}$ by screening have clearly demonstrated how hypothyroidism-related mental retardation can be successfully prevented [18-20]. On the other hand, while it is evident that early and adequate treatment can avoid serious sequelae, numerous studies have reported subtle but statistically significant neurological deficits in children with $\mathrm{CH}$ detected by screening when compared to unaffected individuals [21-23].

The initial severity of $\mathrm{CH}$ may be responsible for a less than ideal outcome. Indeed, evidence from multiple followup studies conducted in the United States and in Europe indicate that patients with lower T4 and more delayed skeletal maturation at the time of diagnosis by screening are more likely to exhibit subnormal cognitive skills [24-26]. Less obvious appears the effects of other variables: one study has shown that the timing of treatment initiation does not affect outcome [27], while other studies have demonstrated that the age at the start of treatment is correlated with neurological outcome in children with $\mathrm{CH}$ even after the introduction of the neonatal screening [18-21]. In addition, another study has indicated that higher initial L-thyroxine dose and faster time to normalization of thyroid function are important in preventing neurodevelopmental impairment [28].

Another variable thought to be an important prognostic factor for intellectual outcome is compliance to L-thyroxine treatment $[19,29,30]$. In a Norwegian study, neuropsychological tests administered at the mean age of 20 years to subjects with $\mathrm{CH}$ diagnosed by neonatal screening program have shown that their mean serum T4 level during the second year of life was a strong predictor of their verbal IQ [21]. In a German study of patients with $\mathrm{CH}$ with an early onset of treatment ( 9 days) and high initial L-thyroxine dose $(14 \mu \mathrm{g} / \mathrm{kg} /$ day $)$, a decreased IQ score was correlated with poor compliance rather than with the severity of $\mathrm{CH}$ [31]. It appears that the discontinuation of L-thyroxine treatment experienced by our patient does not exclusively affect less affluent countries or families of low socioeconomic status. A retrospective analysis in the United States published in 2010 revealed that, by age of 3 years, the percentage of children with $\mathrm{CH}$ diagnosed by neonatal screening who had discontinued thyroxine replacement was $38 \%$, and it was similar between Medicaid-enrolled and privately insured children [32]. While it is conceivable that some of these children were affected by transient hypothyroidism, many others may have been affected by permanent $\mathrm{CH}$, like our patient, and thus are at risk for significant long-term sequelae especially if they are not treated adequately during the first three years of life until brain development is complete.

In conclusion, since neonatal screening for congenital hypothyroidism has been introduced, early L-thyroxine treatment has virtually eliminated hypothyroidism-related growth failure and severe neurological impairment. However, our patient demonstrates that prolonged lack of treatment due to poor compliance (despite early thyroid hormone replacement) may still be responsible for significant growth failure and psychomotor delay during childhood and possible permanent neurological deficits. This case emphasizes the importance of a consistent adherence to treatment in 
preventing such complications, especially in infancy and early childhood.

\section{References}

[1] S. R. Rose, R. S. Brown, T. Foley et al., "Update of newborn screening and therapy for congenital hypothyroidism," Pediatrics, vol. 117, no. 6, pp. 2290-2303, 2006.

[2] J. Deladoëy, J. Ruel, Y. Giguère, and G. Van Vliet, "Is the incidence of congenital hypothyroidism really increasing? A 20year retrospective population-based study in Québec," Journal of Clinical Endocrinology and Metabolism, vol. 96, no. 8, pp. 2422-2429, 2011.

[3] J. P. Brosco, M. Mattingly, and L. M. Sanders, "Impact of specific medical interventions on reducing the prevalence of mental retardation," Archives of Pediatrics and Adolescent Medicine, vol. 160, no. 3, pp. 302-309, 2006.

[4] G. J. Frost and J. M. Parkin, "Management of patients with congenital hypothyroidism," British Medical Journal, vol. 290, no. 6480 , pp. 1485-1489, 1985.

[5] J. A. Hulse, "Outcome for congenital hypothyroidism," Archives of Disease in Childhood, vol. 59, no. 1, pp. 23-29, 1984.

[6] H. Bucher, A. Prader, and R. Illig, "Head circumference, height, bone age and weight in 103 children with congenital hypothyroidism before and during thyroid hormone replacement," Helvetica Paediatrica Acta, vol. 40, no. 4, pp. 305-316, 1985.

[7] L. Moschini, P. Costa, E. Marinelli et al., "Longitudinal assessment of children with congenital hypothyroidism detected by neonatal screening," Helvetica Paediatrica Acta, vol. 41, no. 5, pp. 415-424, 1986.

[8] L. Moreno, H. Ythier, G. A. Loeuille, M. F. Lebecq, J. L. Dhondt, and J. P. Farriaux, "Etude de la croissance et de la maturation osseuse au cours de l'hypotyroidie congenitale depistee en periode neonatale. A propos de 82 observations," Archives Francaises de Pediatrie, vol. 46, no. 10, pp. 723-728, 1989.

[9] D. B. Grant, "Growth in early treated congenital hypothyroidism," Archives of Disease in Childhood, vol. 70, no. 6, pp. 464468, 1994.

[10] R. Aronson, R. M. Ehrlich, J. D. Baily, and J. F. Rovet, "Growth in children with congenital hypothyroidism detected by neonatal screening," Journal of Pediatrics, vol. 116, no. 1, pp. 33-37, 1990.

[11] S. Heyerdahl, A. Ilicki, J. Karlberg, B. F. Kase, and A. Larsson, "Linear growth in early treated children with congenital hypothyroidism," Acta Paediatrica, vol. 86, no. 5, pp. 479-483, 1997.

[12] Z. Dickerman and L. De Vries, "Prepubertal and pubertal growth, timing and duration of puberty and attained adult height in patients with congenital hypothyroidism $(\mathrm{CH})$ detected by the neonatal screening programme for $\mathrm{CH}-$ a longitudinal study," Clinical Endocrinology, vol. 47, no. 6, pp. 649-654, 1997.

[13] M. Salerno, M. Micillo, S. Di Maio et al., "Longitudinal growth, sexual maturation and final height in patients with congenital hypothyroidism detected by neonatal screening," European Journal of Endocrinology, vol. 145, no. 4, pp. 377$383,2001$.

[14] P. Bain and J.-E. Toublanc, "Adult height in congenital hypothyroidism: prognostic factors and the importance of compliance with treatment," Hormone Research, vol. 58, no. 3, pp. 136-142, 2002.
[15] B. Boersma, B. J. Otten, G. B. A. Stoelinga, and J. M. Wit, "Catch-up growth after prolonged hypothyroidism," European Journal of Pediatrics, vol. 155, no. 5, pp. 362-367, 1996.

[16] J. Alm, A. Larsson, and R. Zetterstrom, "Congenital hypothyroidism in Sweden. Psychomotor development in patients detected by clinical signs and symptoms," Acta Paediatrica Scandinavica, vol. 70, no. 6, pp. 907-912, 1981.

[17] G. J. Frost and J. M. Parkin, "A comparison between the neurological and intellectual abnormalities in children and adults with congenital hypothyroidism," European Journal of Pediatrics, vol. 145, no. 6, pp. 480-484, 1986.

[18] W. F. Simons, P. W. Fuggle, D. B. Grant, and I. Smith, "Intellectual development at 10 years in early treated congenital hypothyroidism," Archives of Disease in Childhood, vol. 71, no. 3, pp. 232-234, 1994.

[19] J. Simoneau-Roy, S. Marti, C. Deal, C. Huot, P. Robaey, and G. Van Vliet, "Cognition and behavior at school entry in children with congenital hypothyroidism treated early with high-dose levothyroxine," Journal of Pediatrics, vol. 144, no. 6, pp. 747752, 2004.

[20] S. Bargagna, D. Dinetti, A. Pinchera et al., "School attainments in children with congenital hypothyroidism detected by neonatal screening and treated early in life," European Journal of Endocrinology, vol. 140, no. 5, pp. 407-413, 1999.

[21] B. Oerbeck, K. Sundet, B. F. Kase, and S. Heyerdahl, "Congenital hypothyroidism: influence of disease severity and L-thyroxine treatment on intellectual, motor, and school-associated outcomes in young adults," Pediatrics, vol. 112, no. 4, pp. 923930, 2003.

[22] J. F. Rovet, "Long-term neuropsychological sequelae of earlytreated congenital hypothyroidism: effects in adolescence," Acta Paediatrica, vol. 88, no. 432, pp. 88-95, 1999.

[23] J. F. Rovet, "In search of the optimal therapy for congenital hypothyroidism," Journal of Pediatrics, vol. 144, no. 6, pp. 698700, 2004.

[24] G. H. Murphy, J. A. Hulse, I. Smith, and D. B. Grant, "Congenital hypothyroidism: physiological and psychological factors in early development," Journal of Child Psychology and Psychiatry and Allied Disciplines, vol. 31, no. 5, pp. 711-725, 1990.

[25] S. L. Tillotson, P. W. Fuggle, I. Smith, A. E. Ades, and D. B. Grant, "Relation between biochemical severity and intelligence in early treated congenital hypothyroidism: a threshold effect," British Medical Journal, vol. 309, no. 6952, pp. 440-445, 1994.

[26] M. J. E. Kempers, L. van der Sluijs Veer, R. W. G. Nijhuis-van der Sanden et al., "Neonatal screening for congenital hypothyroidism in The Netherlands: cognitive and motor outcome at 10 years of age," Journal of Clinical Endocrinology and Metabolism, vol. 92, no. 3, pp. 919-924, 2007.

[27] M. J. E. Kempers, L. van der Sluijs Veer, M. W. G. Nijhuisvan der Sanden et al., "Intellectual and motor development of young adults with congenital hypothyroidism diagnosed by neonatal screening," Journal of Clinical Endocrinology and Metabolism, vol. 91, no. 2, pp. 418-424, 2006.

[28] K. A. Selva, A. Harper, A. Downs, P. A. Blasco, and S. H. LaFranchi, "Neurodevelopmental outcomes in congenital hypothyroidism: comparison of initial T4 dose and time to reach target T4 and TSH," Journal of Pediatrics, vol. 147, no. 6, pp. 775-780, 2005.

[29] J. J. Bongers-Schokking, H. M. Koot, D. Wiersma, P. H. Verkerk, and S. M. P. F. De Keizer-Schrama, "Influence of timing and dose of thyroid hormone replacement on development in infants with congenital hypothyroidism," Journal of Pediatrics, vol. 136, no. 3, pp. 292-297, 2000. 
[30] S. Heyerdahl, "Treatment variables as predictors of intellectual outcome in children with congenital hypothyroidism," European Journal of Pediatrics, vol. 155, no. 5, pp. 357-361, 1996.

[31] A. Gruters, K. P. Liesenkoetter, M. Zapico et al., "Results of the screening program for congenital hypothyroidism in Berlin (1978-1995)," Experimental Clinical Endocrinology and Diabetes, vol. 105, supplement 4, pp. 28-31, 1997.

[32] A. R. Kemper, L. Ouyang, and S. D. Grosse, "Discontinuation of thyroid hormone treatment among children in the United States with congenital hypothyroidism: findings from health insurance claims data," BMC Pediatrics, vol. 10, article 9, 2010. 


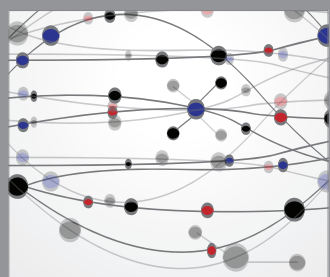

The Scientific World Journal
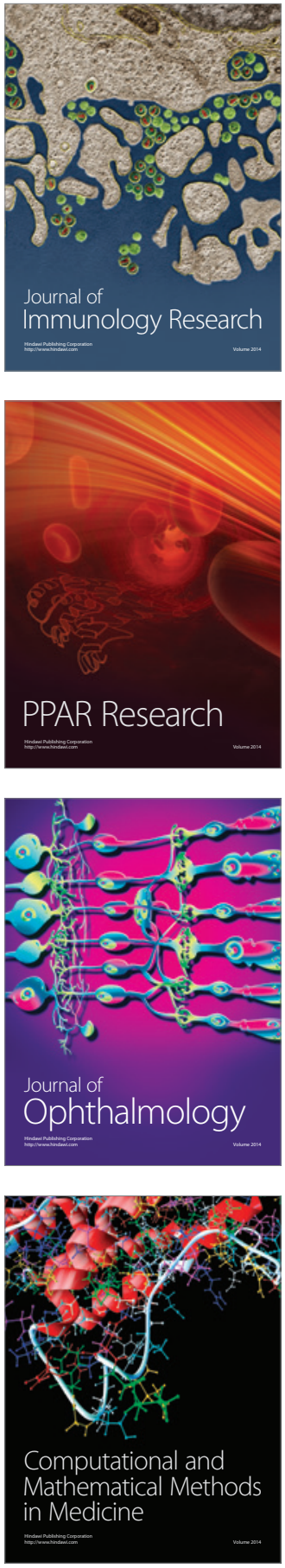

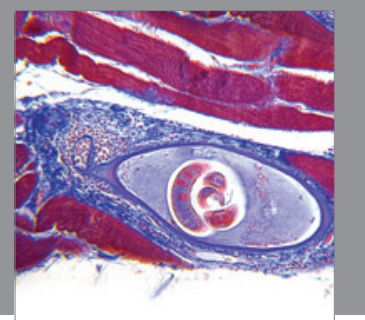

Gastroenterology

Research and Practice
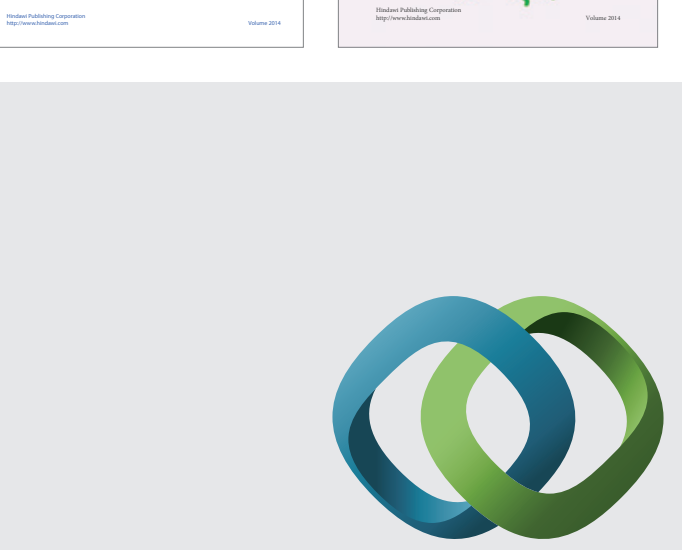

\section{Hindawi}

Submit your manuscripts at

http://www.hindawi.com
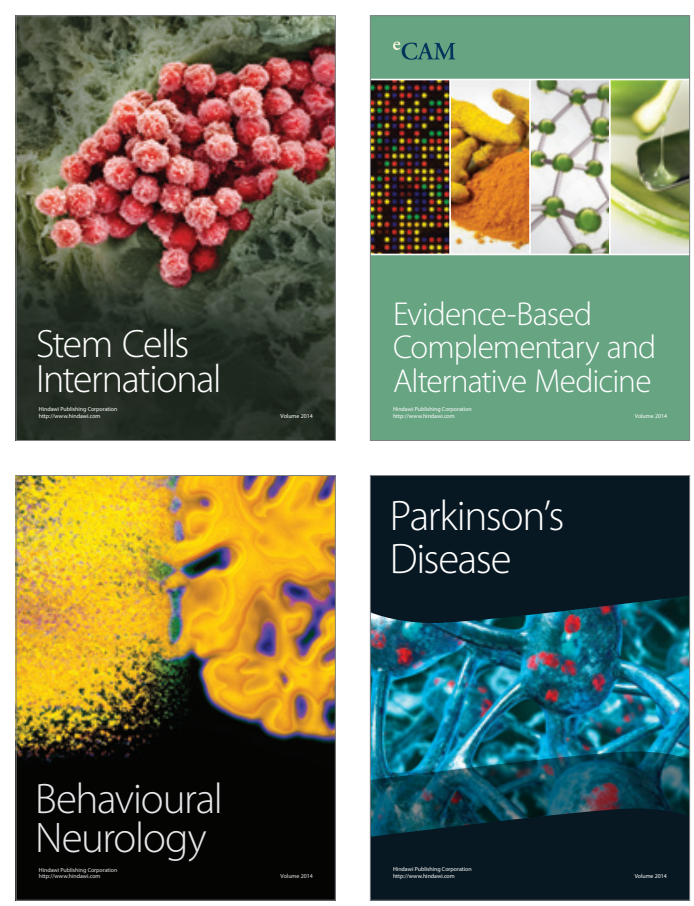

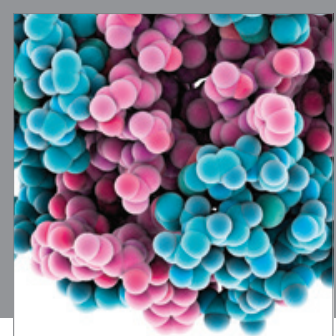

Journal of
Diabetes Research

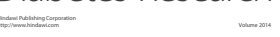

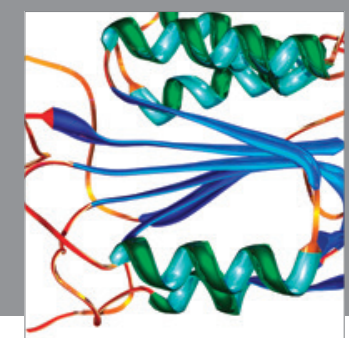

Disease Markers
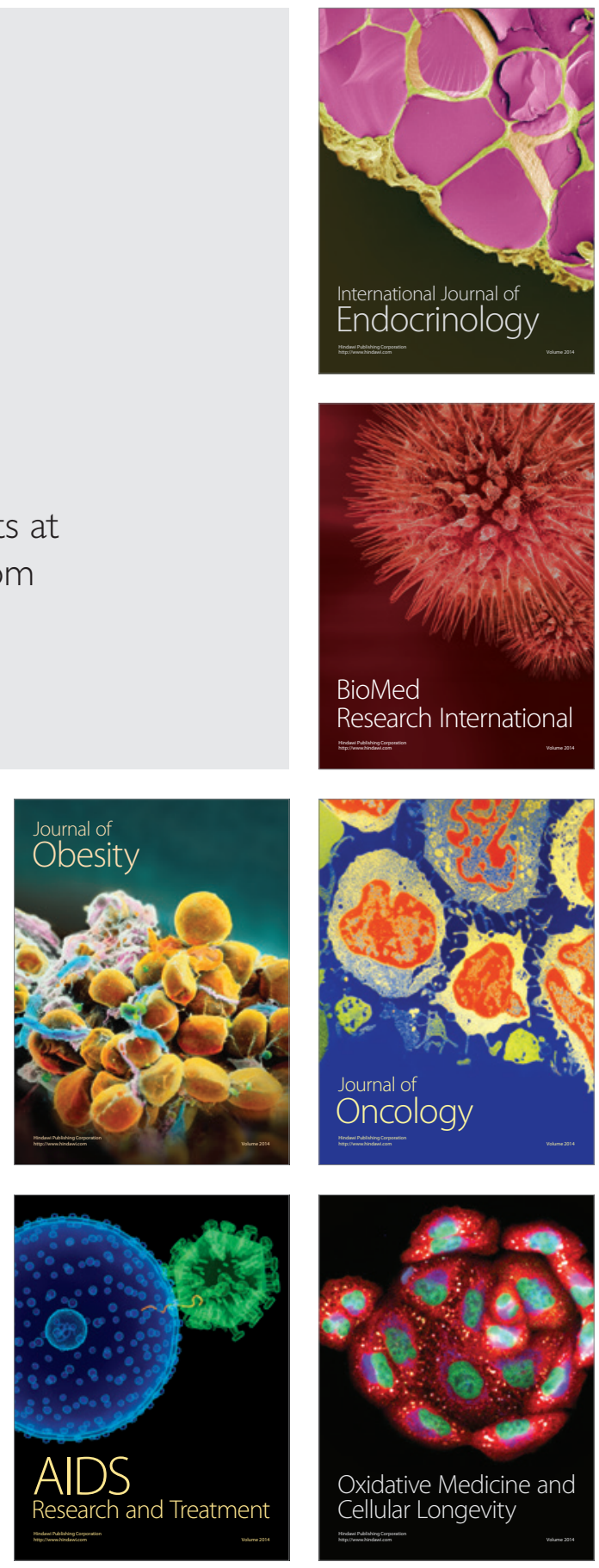